\title{
The residents' mental health status and community's role during the COVID-19 pandemic: a community-based cross-sectional study in China
}

\author{
Simin $\mathrm{Li}^{1,2,3}$, Zhiyu $\mathrm{Ye}^{1,2,3}$, Chunping $\mathrm{Du}^{1,2,3}$, Quan Wei ${ }^{1,2}$, Chengqi He ${ }^{1,2}$ \\ ${ }^{1}$ Department of Rehabilitation Medicine Center, West China Hospital, Sichuan University, Chengdu, China; ${ }^{2}$ Key Laboratory of Rehabilitation \\ Medicine in Sichuan Province, Chengdu, China; ${ }^{3}$ West China School of Nursing, Sichuan University, Chengdu, China \\ Contributions: (I) Conception and design: S Li, Z Ye; (II) Administrative support: C Du, Q Wei, C He; (III) Provision of study materials or patients: S \\ Li, Z Ye; (IV) Collection and assembly of data: S Li, Z Ye, C Du, C He; (V) Data analysis and interpretation: S Li, Q Wei; (VI) Manuscript writing: \\ All authors; (VII) Final approval of manuscript: All authors. \\ Correspondence to: Chunping Du, BS. Professor, Department of Rehabilitation Medicine Center, West China Hospital/West China School of \\ Medicine, Key Laboratory of Rehabilitation Medicine in Sichuan Province, Sichuan University, 37 Guoxue Lane, Wuhou District, Chengdu, China. \\ Email: ducp118@163.com.
}

Background: The related research of coronavirus disease 2019 (COVID-19) pandemic on the mental health of community residents is still lacking. Here we reported the mental health status of Chinese residents as well as the community's prevention and control during the pandemic period of COVID-19 and further explored the influencing factors of mental status.

Methods: In this cross-sectional study, convenience sampling and snowball sampling methods were adopted from February 16 to February 23, 2020, and Chinese community residents were included according to the inclusion and exclusion criteria. Three questionnaires, including General Anxiety Disorder 7 (GAD-7), Patient Health Questionnaire 9 (PHQ-9), and a self-designed "Community prevention and control questionnaire”, were used. A multivariate linear regression analysis was conducted to analyze the impact factors of anxiety and depression.

Results: A total of 3,001 community residents were included in this study. In total, $85.6 \%$ and $83.7 \%$ of participants had minimal anxiety and depression, respectively. Among all the community residents, $16.6 \%$ of participants proved that the communities they lived in had confirmed cases. $95.3 \%$ of participants reported that the residents were screened for mobility and contact history. $97.8 \%$ of participants reported the entrance and exit of the community were managed in their communities. There were $97.5 \%$ and $99 \%$ of participants needed to take body temperature and wear masks in their communities. Ninety-two percent (92\%) of communities have their public areas and facilities disinfected daily, and $95.4 \%$ of communities have conducted health education about COVID-19. Factors including gender, education level, chronic illness, the frequency of going out, achieving information about COVID-19 by community and newspaper, and confirmed cases in the community, show association with community residents' anxiety and depression.

Conclusions: The vast majority of Chinese residents have little anxiety and depression, and most communities have adopted standardized control measures following the government's regulations and policy, which plays a vital role in the control of COVID-19 and improving residents' anxiety and depression.

Keywords: COVID-19; coronavirus; mental health; anxiety; depression; community; impact factors

Submitted Sep 10, 2020. Accepted for publication Oct 20, 2020.

doi: $10.21037 /$ atm-20-6687

View this article at: http://dx.doi.org/10.21037/atm-20-6687 


\section{Introduction}

Coronavirus disease 2019 (COVID-19) outbroke in Wuhan, China, in December 2019 (1), and has been declared as a Public Health Emergency of International Concern (PHEIC) by the World Health Organization (WHO) (2). COVID-19 kept spreading around the globe, and the number of confirmed cases kept growing daily. By March 28, 2020, 202 countries, areas, or territories were reported cases of COVID-19 (3), and 575,444 people worldwide were diagnosed with COVID-19, including 85,228 cases in the United States of America, 82,230 cases in China, and 86,498 cases in Italy (4). China is the first country infected with COVID-19 and responded quickly and formulated a series of comprehensive prevention and control measures from the community to detect cases early and prevent the pandemic from spreading at the initial stage of the pandemic (5). The community was requested full participation in the management of self-isolation and enhancement of public compliance. Epidemiological investigation and close contact management were brought in to act in the community (5). Also, many communities were requested to strengthen the management of population movement, health condition monitoring, medical observation, isolation of persons from the pandemic-center, and contact tracing (6), which may last for an unpredictable time. Therefore, most community residents had to stay home for isolation. The implications of comprehensive and strict prevention measures for reducing the spread of contagious COVID-19 may lead to severe distress, symptoms of anxiety and depression in community residents. Hence, the psychological status of community residents needs to be taken into account during the COVID-19 pandemic, an essential part of the prevention and control of the COVID-19 (7).

At present, the information and research on the community residents' mental health during the COVID-19 pandemic is still lacking. In this study, we conducted a crosssectional study to investigate Chinese residents' anxiety and depression as well as the status of community prevention and control in the Chinese mainland, then further explored the influencing factors of mental status to provide support for targeted psychological interventions and community prevention.

We present the following article in accordance with the SURGE reporting checklist (available at http://dx.doi. org/10.21037/atm-20-6687).

\section{Methods}

\section{Study design and participants}

A cross-sectional survey on community residents was conducted in the Chinese mainland from February 16 to February 23, 2020. A convenience sampling and snowball sampling were adopted. The study's samples were formed of 3,001 residents in the community from 30 provinces or districts. West China Hospital approved the study of the Sichuan University Biomedical Research Ethics Committee [No. 2020(163)]. All participants complete electronic informed consent and all procedures performed in this study involving human participants were in accordance with the Declaration of Helsinki (as revised in 2013). Community residents were invited to participate in this study if they, (I) lived in China mainland since January 1, 2020, (II) agreed to participate in the study and signed informed consent, (III) could fully understand all the items in the scale, (IV) could use a mobile phone and operate the questionnaire filling tool, (V) can complete all items of the questionnaire. Also, questionnaires would be excluded from analysis when the completed time was less than 3 minutes or more than 30 minutes.

\section{Instrument}

\section{Anxiety}

The GAD-7 is a brief self-reported scale and efficient tool for screening General Anxiety Disorder (GAD) with seven items rated on a 4-point Likert-scale ranging from 0 (not at all) to 3 (nearly daily) $(8,9)$. The total score is minimal [0-4], mild [5-9], moderate [10-14], and severe [15-21] anxiety symptoms, respectively. In the present study, the Cronbach's a was 0.92 , test-retest reliability was good (intraclass correlation $=0.83)(8)$.

\section{Depression}

The Patient Health Questionnaire 9 (PHQ-9) is a widely used instrument to measure the depression of the subjects, which includes nine questions rated on a four-point scale ranging from 0 (not at all) to 3 (nearly daily). A total score ranging from 0 to 27 is categorized into minimal [0-4], mild [5-9], moderate [10-14], moderately severe [15-19], and severe [20-27] (10). In the PHQ Primary Care Study, the Cronbach's $\alpha$ was 0.89 , test-retest reliability excellent 
(intraclass correlation $=0.84)(11)$.

\section{The status of community prevention and control}

To evaluate the specific problems of the status of community prevention and control during the COVID-19, we designed a "Community prevention and control questionnaire" under the guidance of two specialist nursing professors, which focused on the prevention measures the community had taken during the COVID-19 pandemic. This questionnaire consists of 7 items, and participants should respond using "Yes" or "No". From item 1, we could learn about the situation of confirmed cases around the participants. Items 2 to 6 evaluate the implementation of the community's prevention and control measures, including personnel mobility management, body temperature measurement, wearing of masks, disinfection of public areas. Item 7 evaluates the community's health education about COVID-19.

\section{Procedure and data collection}

A networking questionnaire tool (https://www.wjx.cn) was adopted to transfer the paper-based questionnaire into a web page before we started the survey. One person typed the questionnaire; another person checked whether the questionnaire was consistent with the paper version. After the questionnaire had been completed, three medical staff and seven community residents were invited to fill out this questionnaire to investigate whether incomprehensible items or difficulties were completing the questionnaire. Through the Chinese Association of Rehabilitation, Association of Community Rehabilitation, we distributed the questionnaire to communities in different provinces and invited eligible community residents to take part. An electronic informed consent was obtained from community members involved before collecting data. The questionnaire was collected from February 16, 2020, to February 23, 2020.

\section{Statistical analysis}

Data analysis was performed with SPSS version 21.0 (IBM Corporation, Armonk, NY, USA), assigning a significance level of $5 \%(\mathrm{P}<0.05)$. Descriptive statistics for socialdemographic variables, the status of community prevention and control, are presented as count (\%), as well as anxiety and depression due to their abnormal distribution. The associations between social-demographic variables, the status of community prevention and control, anxiety, and depression were examined by the multivariate linear regression analysis at the entering regression model, the variables of GAD-7 and PHQ-9 were converted to a normal distribution by the Turkey method. We defined it shows collinearity among independent variables when the variance inflation factor $(\mathrm{VIF}) \geq 2$.

\section{Results}

Three thousand one community residents were included in this study, $72.2 \%$ of whom were women, $85.0 \%$ were in the young and middle-aged crowd. More than half of the community members involved were married. There were $97 \%$ of participants in Han nationality. $36.3 \%$ of participants were undergraduate or more, and $77.0 \%$ of participants were not medical personnel. $91.3 \%$ of participants were in good health and without any chronic illness. There were $33.0 \%$ of participants never going out, and $58.9 \%$ of participants restricted the frequency of going out to no more than six times a week. Half were waiting for work at home. There were $68.6 \%$ of participants not living alone and $60 \%$ living in an urban city. TV News $(92.1 \%)$, WeChat $(88.8 \%)$, community $(78.2 \%)$, web page $(75.7 \%)$ and other apps $(74.0 \%)$ were the main approach to receive information about COVID-19 (Table 1).

In general, there were $85.6 \%$ and $83.7 \%$ of participants with minimal anxiety and depression. $11.5 \%$ and $13.3 \%$ of participants had experienced mild anxiety and depression, respectively. $2.2 \%$ and $2.0 \%$ of participants stated moderate anxiety and depression, only $0.7 \%$ and $0.3 \%$ were severe. Meanwhile, moderately severe depression was $0.7 \%$ (Figures 1,2).

The data in Table 2 shows the status of community prevention and control. $16.6 \%$ of participants declared there were confirmed cases in the communities they lived in. A total of $95.3 \%$ reported that residents were screened for mobility and contact history. $97.8 \%$ of participants showed that their communities managed the entrance and exit of the community. There were $97.5 \%$, and $99 \%$ of participants were required to take body temperature and wear masks in their communities, respectively. $92 \%$ of communities had their public areas and facilities disinfected daily, and $95.4 \%$ of communities had conducted health education about COVID-19.

The data in Table 3 shows the influencing factors of anxiety and depression by multivariate linear regression 
Table 1 Demographic characteristics $(\mathrm{n}=3,001)$

\begin{tabular}{|c|c|}
\hline Variables & $\mathrm{n}(\%)$ \\
\hline \multicolumn{2}{|l|}{ Gender } \\
\hline Male & $833(27.8)$ \\
\hline Female & $2,168(72.2)$ \\
\hline \multicolumn{2}{|l|}{ Age, years } \\
\hline$<18$ & $431(14.4)$ \\
\hline $18-64$ & $2,552(85.0)$ \\
\hline$\geq 65$ & $18(0.6)$ \\
\hline \multicolumn{2}{|l|}{ Nation } \\
\hline Han nationality & $2,910(97.0)$ \\
\hline Minority nationality & $91(3.0)$ \\
\hline \multicolumn{2}{|l|}{ Marital status } \\
\hline Unmarried & $893(29.8)$ \\
\hline Married & $1,990(66.3)$ \\
\hline Divorced & $100(3.3)$ \\
\hline Widowed & $18(0.6)$ \\
\hline \multicolumn{2}{|l|}{ Education level } \\
\hline Elementary school or less & $133(4.5)$ \\
\hline Middle school and High school & $1,063(35.4)$ \\
\hline Professional education & $715(23.8)$ \\
\hline Undergraduate or more & $1,090(36.3)$ \\
\hline \multicolumn{2}{|l|}{ Domicile } \\
\hline Urban & $1,783(59.4)$ \\
\hline Rural & $1,218(40.6)$ \\
\hline \multicolumn{2}{|l|}{ Occupation } \\
\hline Medical personnel & $689(23.0)$ \\
\hline Others & $2,312(77.0)$ \\
\hline \multicolumn{2}{|l|}{ Chronic illness } \\
\hline Yes & $262(8.7)$ \\
\hline No & $2,739(91.3)$ \\
\hline \multicolumn{2}{|l|}{ The frequency of going out } \\
\hline Never & $989(33.0)$ \\
\hline 1 to 6 times & $1,768(58.9)$ \\
\hline$\geq 7$ times & $244(8.1)$ \\
\hline
\end{tabular}

Table 1 (continued)
Table 1 (continued)

\begin{tabular}{lc}
\hline Variables & $\mathrm{n}(\%)$ \\
\hline Working status & $980(32.7)$ \\
Return to work & $1,382(46.1)$ \\
Wait for work at home & $270(9.0)$ \\
Home quarantine & $369(12.3)$ \\
Others & \\
Dwelling status & $939(31.3)$ \\
Living alone & $2,062(68.7)$ \\
Living with others & \\
The approach of achieving knowledge about COVID-19 & $2,765(92.1)$ \\
TV News & $2,665(88.8)$ \\
WeChat & $2,347(78.2)$ \\
Community & $2,271(75.7)$ \\
Web page & $2,222(74.0)$ \\
Other APP & $627(20.9)$ \\
Newspaper & $279(9.3)$ \\
Others & \\
\hline
\end{tabular}

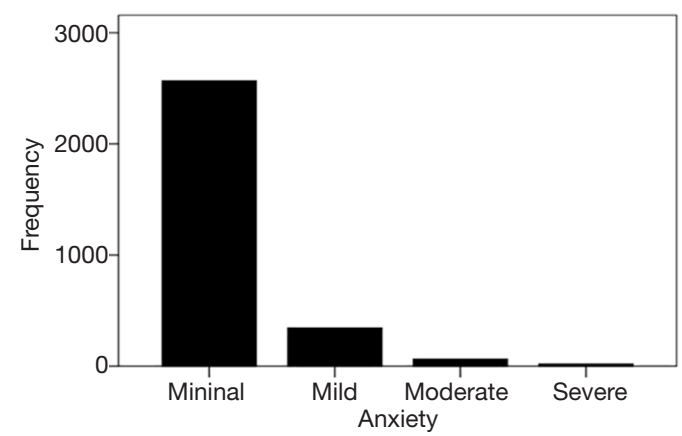

Figure 1 The anxiety of Chinese residents.

analysis. In terms of anxiety, the prevalence of males is higher than females $(\mathrm{P}=0.000)$. Unmarried people's anxiety is different from other marriage situations $(\mathrm{P}=0.004)$. Anxiety and depression are negatively correlated with academic qualifications $(\mathrm{P}=0.000)$. Residents with or without chronic diseases have distinct levels of anxiety and depression $(\mathrm{P}=0.000)$. The frequency of going out is 
positively correlated with anxiety. The frequency of going out ranging from 0 to 6 shows a significant difference with others in depression $(\mathrm{P}=0.001)$. The prevalence of anxiety and depression among residents who were receiving information from the community $(\mathrm{P}=0.045, \mathrm{P}=0.027)$, newspaper $(\mathrm{P}=0.000, \mathrm{P}=0.000)$ related to COVID-19 is lower than those who did not. The web page's information involved also could evacuate residents' anxiety $(\mathrm{P}=0.000)$. Residents with confirmed cases in their communities were more likely to experience anxiety and depression $(\mathrm{P}=0.000$, $\mathrm{P}=0.000)$. There is less coincidence to obtain depression for residents whose communities disinfected public areas daily, while the health education of COVID-19 in the community reduced the incidence of depression.

\section{Discussion}

It is well-known that acute stress itself in disasters and public health emergencies could have a continuing effect on physical and psychological health $(12,13)$. During the

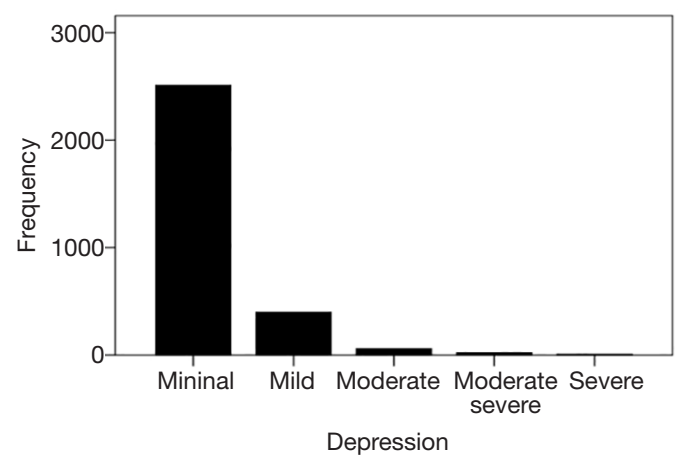

Figure 2 The depression of Chinese residents. pandemic, the community residents must be managed to cut off the potential transmission of the disease. Moreover, the number of infected cases, strict prevention policy, a temporary shortage of medical masks and alcohol across the country may further exacerbate the residents' fear, panic, and distress during the pandemic of COVID-19. The mental health of community residents may have problems under this uncommon situation and should not be overlooked. It is essential to support community residents' mental health for better control of the pandemic. Previously published researches discussed the psychological status of frontline medical staff, and several types of online mental health services have been widely provided for those in need during the pandemic in China (14-16). Whereas, there were deficient attention and research focused on community residents.

From the present study's outcomes, most of the community residents involved exhibit little anxiety and depression, while there are $14.4 \%$ and $16.3 \%$ of participants obtaining varying degrees of anxiety and depression, which is higher than medical staff's proportion (13.5\%) in Zhou Zhu's survey (17). However, both of the incidences of anxiety and depression are lower than Huang's study (34.0\% and $18.1 \%$ ), which also focuses on the Chinese population with the questionnaire GAD-7 and the Center for Epidemiology Scale for Depression (CES-D) (18). The difference may be correlated to the sample size $(n=603)$ and the number of medical staff $(\mathrm{n}=182)$.

In terms of community prevention and control measures, the vast majority of communities have adopted standardized control measures following the regulations of the Central People's Government of the People's Republic of China. For instance, doctors screening for residents' mobility,

Table 2 The status of community prevention and control

\begin{tabular}{|c|c|c|}
\hline Variables & \multicolumn{2}{|c|}{ Category, n (\%) } \\
\hline Confirmed cases in the community & $498(16.6)$ & $2,503(83.4)$ \\
\hline Your community had screened for residents' mobility and contact history & $2,859(95.3)$ & $142(4.7)$ \\
\hline The community had managed the entrance and exit of the community & $2,935(97.8)$ & $66(2.2)$ \\
\hline The community had required all personnel in and out to wear masks & $2,970(99.0)$ & $31(1.0)$ \\
\hline The community had disinfected the public areas and facilities every day & $2,761(92.0)$ & $240(8.0)$ \\
\hline The community had conducted health education about COVID-19 & $2,863(95.4)$ & $138(4.6)$ \\
\hline
\end{tabular}


Table 3 Results of the multiple linear regression analysis with the anxiety and depression

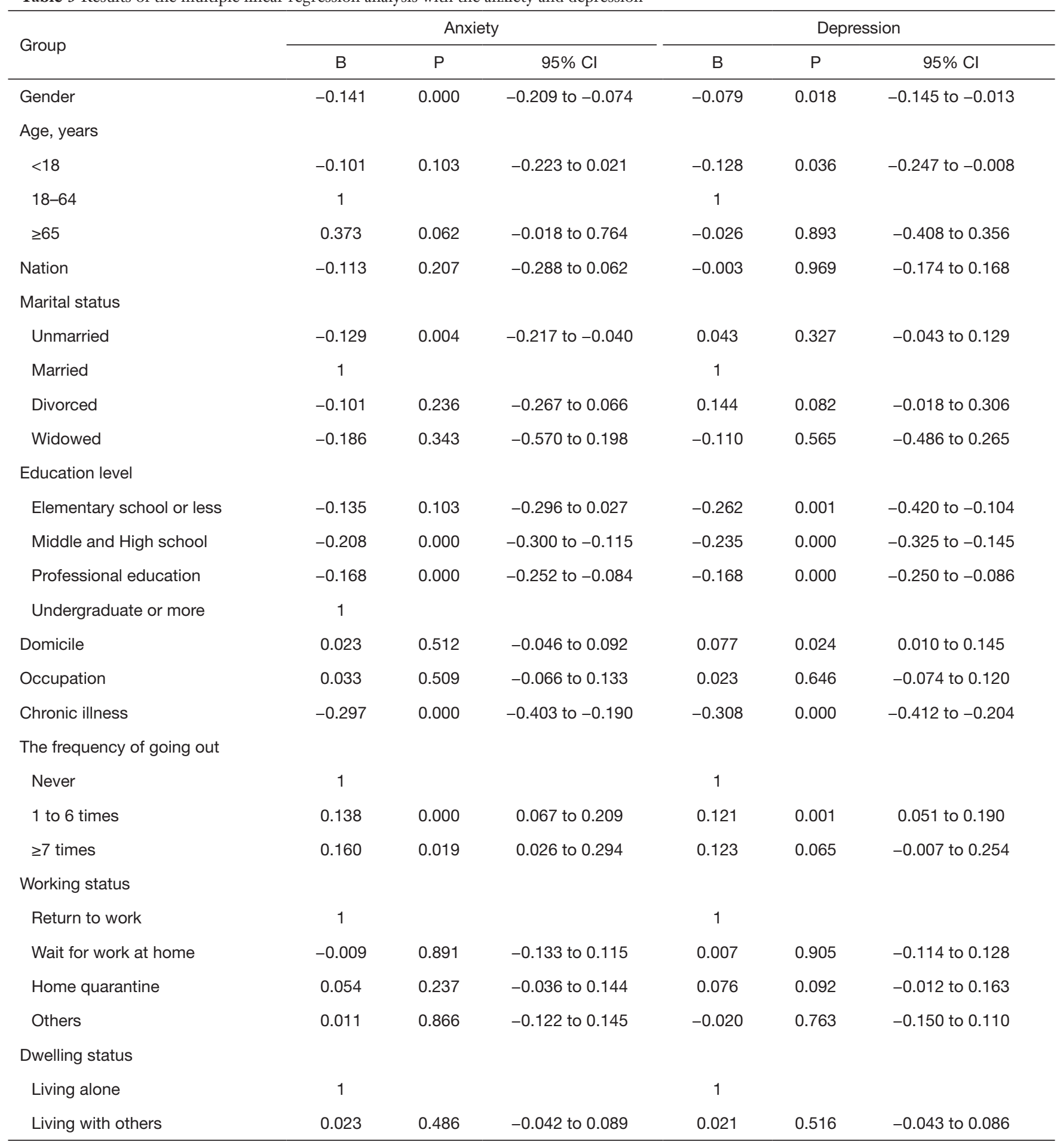

Table 3 (continued) 
Table 3 (continued)

\begin{tabular}{|c|c|c|c|c|c|c|}
\hline Group & \multicolumn{3}{|c|}{ Anxiety } & \multicolumn{3}{|c|}{ Depression } \\
\hline \multicolumn{7}{|c|}{ The approach of achieving knowledge about COVID-19 } \\
\hline TV News & -0.067 & 0.262 & -0.184 to 0.050 & -0.053 & 0.359 & -0.167 to 0.061 \\
\hline WeChat & 0.047 & 0.358 & -0.053 to 0.148 & 0.034 & 0.498 & -0.064 to 0.132 \\
\hline Webpage & 0.143 & 0.000 & 0.064 to 0.221 & 0.073 & 0.062 & -0.004 to 0.149 \\
\hline Other APP & -0.004 & 0.927 & -0.081 to 0.074 & 0.007 & 0.866 & -0.069 to 0.082 \\
\hline Newspaper & -0.194 & 0.000 & -0.273 to -0.116 & -0.150 & 0.000 & -0.227 to -0.073 \\
\hline Others & 0.091 & 0.091 & -0.015 to 0.196 & 0.058 & 0.271 & -0.045 to 0.161 \\
\hline $\begin{array}{l}\text { Screen for mobility and contact } \\
\text { history }\end{array}$ & -0.064 & 0.369 & -0.205 to 0.076 & 0.000 & 0.996 & -0.137 to 0.138 \\
\hline $\begin{array}{l}\text { Managed entrance and exit of } \\
\text { community }\end{array}$ & -0.039 & 0.748 & -0.280 to 0.201 & 0.041 & 0.734 & -0.194 to 0.275 \\
\hline $\begin{array}{l}\text { Required all to monitor body } \\
\text { temperature }\end{array}$ & -0.080 & 0.549 & -0.340 to 0.181 & -0.098 & 0.448 & -0.353 to 0.156 \\
\hline Required all to wear masks & 0.191 & 0.341 & -0.202 to 0.583 & 0.199 & 0.310 & -0.185 to 0.582 \\
\hline $\begin{array}{l}\text { Disinfected the public areas and } \\
\text { facilities everyday }\end{array}$ & -0.205 & 0.001 & -0.327 to -0.083 & -0.114 & 0.060 & -0.233 to 0.005 \\
\hline
\end{tabular}

managing the entrance and exit of the community, monitoring body temperature and requiring wearing masks for all, and disinfecting the public areas and facilities daily. Also, we found that all communities in our study had conducted health education about COVID-19, which was an essential and efficient approach to evacuate the residents' depression after impact factor analysis. $8.0 \%$ of communities do not disinfect the public areas and facilities daily, which may be associated with $40.6 \%$ of participants coming from rural areas, and some local governments reported rural areas are disinfected every 3 days (17).

We also investigated the correlation among social demographics, the status of community prevention and control, as well as individual mental health. The gender, education level, chronic illness, the frequency of going out, receiving information about COVID-19 from community and newspaper, and confirmed cases in the community have a relation with community residents' anxiety and depression. Notably, the education level is negatively correlated with residents' anxiety and depression, which proves the need to strengthen education for low-educated personnel in turn. Meanwhile, the confirmed cases in the community could affect the community residents' mental health due to the high infectivity of COVID-19. What is more, the results indicate the strict prevention measures the community took, for instance, screening for mobility and contact history, managing entrance and exit of community, requiring all to monitor body temperature and wear masks, has no relation with the anxiety and depression of residents.

On the contrary, the community's education and prevention measures have a significant effect on improving residents' anxiety and depression, showing the critical role of the community during the pandemic. And on March 5, 2020 , for further promoting the community prevention 
and education, the Ministry of Civil Affairs of the People's Republic of China has implemented a series of measures to enhance informatization and intellectualization of community-based on the big data (19). Except for the above results, we find there was no difference in anxiety and depression between medical staff and non-medical staff, which may closely relate to community education and prevention as well as the rapid and widespread dissemination of official information on COVID-19 to the community residents could respond the infection disease scientifically and effectively.

This study has several limitations. First, although 3,001 community residents were included in the study, there is possible selection bias: we recruited participants by the members of the Chinese Association of Rehabilitation, Association of Community Rehabilitation, distributing the survey to their provinces resulting in uneven sample sources. There may be systematic differences between those who are included in our study and those not included, whereas the sample size of our study is relatively large and may have little effect on the results. Second, cross-sectional data cannot prove causation between impact factors and the outcome variables. However, the relationship we find here can prove the crucial role of the community in the control of COVID-19 and mental status management.

\section{Conclusions}

In conclusion, although under the uncommon situation of COVID-19 and strict community prevention and control measures, most Chinese residents have minimal anxiety and depression. However, in the face of highly infectious COVID-19, the effective community prevention and control policy played an essential role in disease control, and to some extent, maintaining an excellent psychological status of Chinese residents.

\section{Acknowledgments}

We are grateful to the residents who took part in the study. Members of the Chinese Association of Rehabilitation, Association of Community Rehabilitation, facilitated data collection. Jianmei Zhang, Xuyi Wu, Hongying Jiang filled out and gave meaningful comments on the questionnaire before the investigation. Qian Wang, Siyi Zhu, and Xi Yu gave helpful revision to the manuscript.

Funding: The West China Hospital supported this study, Sichuan University, Chengdu, Sichuan, China [grant number: HX-2019-nCoV-011]. The funding bodies had no role in the design of the study, data collection, analysis, and interpretation of data, and writing of the manuscript.

\section{Footnote}

Reporting Checklist: The authors have completed the SURGE reporting checklist. Available at http://dx.doi. org/10.21037/atm-20-6687

Data Sharing Statement: Available at http://dx.doi. org/10.21037/atm-20-6687

Conflicts of Interest: All authors have completed the ICMJE uniform disclosure form (available at http://dx.doi. org/10.21037/atm-20-6687). The authors have no conflicts of interest to declare.

Ethical Statement: The authors are accountable for all aspects of the work in ensuring that questions related to the accuracy or integrity of any part of the work are appropriately investigated and resolved. All procedures performed in this study involving human participants were in accordance with the Declaration of Helsinki (as revised in 2013). The study was approved by ethics board of West China Hospital, Sichuan University [No. 2020(163)]. All participants complete electronic informed consent.

Open Access Statement: This is an Open Access article distributed in accordance with the Creative Commons Attribution-NonCommercial-NoDerivs 4.0 International License (CC BY-NC-ND 4.0), which permits the noncommercial replication and distribution of the article with the strict proviso that no changes or edits are made and the original work is properly cited (including links to both the formal publication through the relevant DOI and the license). See: https://creativecommons.org/licenses/by-nc-nd/4.0/.

\section{References}

1. Lu H, Stratton CW, Tang YW. Outbreak of pneumonia of unknown etiology in Wuhan, China: The mystery and the miracle. J Med Virol 2020;92:401-2.

2. Division IC. The World Health Organization (WHO) has declared a new type of coronavirus-infected pneumonia as a "public health emergency of international concern": travel and trade restrictions against China are not recommended 2020 [cited 2020 Jan 31]. Available online: 
http://www.nhc.gov.cn/gjhzs/s7952/202001/b196e4f678bc 4447a0e4440f92 dac81b.shtml

3. WHO. Coronavirus disease (COVID-19) outbreak situation 2020 [cited 2020 Mar 28]. Available online: https://www.who.int/emergencies/diseases/novelcoronavirus-2019

4. WHO. Coronavirus disease 2019 (COVID-19) Situation Report-52. WHO; 2020 Mar 28, 2020. Contract No.: 68.

5. Bureau DPaC. Circular on Strengthening Community Prevention and Control of Pneumonia Outbreaks with New Coronavirus Infection. In: Bureau DPaC, editor. National Health Commission of the People's Republic of China: National Health Commission of the Peopl's Republic of China; 2020.

6. Daily C. China' 10 measures to combat epidemicWHO-China report 2020 [cited 2020 Mar 5]. Available online: https://www.chinadaily.com.cn/a/202003/05/ WS5e602befa31012821727c5fa_1.html

7. Health BG. Is mental health a concern for COVID-19? 2020 [cited 2020 February 20]. Available online: https:// blogs.bmj.com/bmjgh/2020/02/20/is-mental-health-aconcern-for-covid-19/

8. Spitzer RL, Kroenke K, Williams JB, et al. A brief measure for assessing generalized anxiety disorder: the GAD-7. Arch Intern Med 2006;166:1092-7.

9. Plummer F, Manea L, Trepel D, McMillan D. Screening for anxiety disorders with the GAD-7 and GAD-2: a systematic review and diagnostic metaanalysis. Gen Hosp Psychiatry 2016;39:24-31.

10. Kroenke K, Spitzer RL, Williams JB. The PHQ-9: validity of a brief depression severity measure. J Gen Intern Med 2001;16:606-13.

11. Teymoori A, Real R, Gorbunova A, et al. Measurement invariance of assessments of depression (PHQ-9)

Cite this article as: $\mathrm{Li} \mathrm{S}$, Ye Z, Du C, Wei Q, He C. The residents' mental health status and community's role during the COVID-19 pandemic: a community-based cross-sectional study in China. Ann Transl Med 2020;8(20):1321. doi: 10.21037/atm-206687 and anxiety (GAD-7) across sex, strata and linguistic backgrounds in a European-wide sample of patients after Traumatic Brain Injury. J Affect Disord 2020;262:278-85.

12. Fan F, Long K, Zhou Y, et al. Longitudinal trajectories of post-traumatic stress disorder symptoms among adolescents after the Wenchuan earthquake in China. Psychol Med 2015;45:2885-96.

13. Cheng SK, Wong CW, Tsang J, et al. Psychological distress and negative appraisals in survivors of severe acute respiratory syndrome (SARS). Psychol Med 2004;34:1187-95.

14. Liu S, Yang L, Zhang C, et al. Online mental health services in China during the COVID-19 outbreak. Lancet Psychiatry 2020;7:e17-8.

15. Chen Q, Liang M, Li Y, et al. Mental health care for medical staff in China during the COVID-19 outbreak. Lancet Psychiatry 2020;7:e15-e16.

16. Duan L, Zhu G. Psychological interventions for people affected by the COVID-19 epidemic. Lancet Psychiatry 2020;7:300-2.

17. Zhu Z, Xu S, Wang H, et al. COVID-19 in Wuhan: Immediate Psychological Impact on 5062 Health Workers. medRxiv. 2020.

18. Huang Y, Zhao N. Generalized anxiety disorder, depressive symptoms and sleep quality during COVID-19 epidemic in China: a web-based cross-sectional survey. medRxiv. 2020.

19. Affairs OotMoC. Guidelines on Informatization Construction and Application of Community Prevention and Control of COVID-19. In: China MoCAotPsRo, editor. 2020.

(English language editor: J. Chapnick) 